University of Texas Rio Grande Valley

ScholarWorks @ UTRGV

$9-29-2021$

\title{
Impaired postprandial skeletal muscle vascular responses to a mixed meal challenge in normoglycaemic people with a parent with type 2 diabetes
}

\author{
Ryan D. Russell \\ The University of Texas Rio Grande Valley, ryan.russell@utrgv.edu \\ Katherine M. Roberts-Thomson \\ Donghua $\mathrm{Hu}$ \\ Timothy Greenaway \\ Andrew C. Betik
}

See next page for additional authors

Follow this and additional works at: https://scholarworks.utrgv.edu/hhp_fac

Part of the Diseases Commons

\section{Recommended Citation}

Russell, R.D., Roberts-Thomson, K.M., Hu, D. et al. Impaired postprandial skeletal muscle vascular responses to a mixed meal challenge in normoglycaemic people with a parent with type 2 diabetes. Diabetologia 65, 216-225 (2022). https://doi.org/10.1007/s00125-021-05572-7

This Article is brought to you for free and open access by the College of Health Professions at ScholarWorks @ UTRGV. It has been accepted for inclusion in Health \& Human Performance Faculty Publications and Presentations by an authorized administrator of ScholarWorks @ UTRGV. For more information, please contact justin.white@utrgv.edu,william.flores01@utrgv.edu. 


\section{Authors}

Ryan D. Russell, Katherine M. Roberts-Thomson, Donghua Hu, Timothy Greenaway, Andrew C. Betik, Lewan Parker, James E. Sharman, Stephen M. Richards, Stephen Rattigan, Dino Premilovac, Glenn D. Wadley, and Michelle A. Keske 


\section{Article}

\section{Impaired postprandial skeletal muscle vascular responses to a mixed meal challenge in normoglycaemic people with a parent with type 2 diabetes}

Ryan D. Russel1 ${ }^{1,2}$, Katherine Roberts-Thomson ${ }^{3}$, Donghua Hu ${ }^{1}$, Timothy Greenaway ${ }^{4}$, Andrew C. Betik ${ }^{3,5}$, Lewan Parker ${ }^{3,5}$, James E. Sharman ${ }^{1}$, Stephen M. Richards ${ }^{4}$, Stephen Rattigan ${ }^{1}$, Dino Premilovac ${ }^{4}$, Glenn D. Wadley ${ }^{3}$ and Michelle A. Keske ${ }^{1,3,5}$

Ryan D. Russell and Katherine Roberts-Thomson are joint first authors.

\footnotetext{
${ }^{1}$ Menzies Institute for Medical Research, University of Tasmania, Hobart, TAS, Australia

${ }^{2}$ Department of Health and Human Performance, College of Health Professions, University of Texas Rio Grande Valley, Brownsville, TX, USA

${ }^{3}$ Institute for Physical Activity and Nutrition (IPAN), School of Exercise and Nutrition Sciences, Deakin University, Geelong, VIC, Australia

${ }^{4}$ Tasmanian School of Medicine, University of Tasmania, Hobart, TAS, Australia

${ }^{5}$ Baker Heart and Diabetes Institute, Melbourne, VIC, Australia
}

Corresponding author: Michelle A. Keske

E-mail: Michelle.Keske@deakin.edu.au

\section{ORCID identifiers:}

RD Russell: 0000-0002-1275-1472

K Roberts-Thomson: 0000-0002-0950-4972

D Hu: 0000-0003-2654-5212

T Greenaway: 0000-0001-5871-3917

AC Betik: 0000-0001-8294-9719

L Parker: 0000-0002-5372-1851

JE Sharman: 0000-0003-2792-0811

SM Richards: 0000-0002-5988-0423 
S Rattigan: 0000-0001-6172-3040

D Premilovac: 0000-0003-2770-4713

GD Wadley: 0000-0002-6617-4359

MA Keske: 0000-0003-4214-7628

Tweet A clinical study led by @KeskeMichelle shows that adult offspring from parents with type 2 diabetes have poor muscle vascular health, even if they have normal blood sugar levels. \#T2D \#SkeletalMuscle @DeakinIPAN@DeakinResearch@TasSchoolMed

Received: 30 April 2021 / Accepted: 22 July 2021 


\begin{abstract}
Aims/hypothesis Microvascular blood flow (MBF) increases in skeletal muscle postprandially to aid in glucose delivery and uptake in muscle. This vascular action is impaired in individuals who are obese or have type 2 diabetes. Whether MBF is impaired in normoglycaemic people at risk of type 2 diabetes is unknown. We aimed to determine whether apparently healthy people at risk of type 2 diabetes display impaired skeletal muscle microvascular responses to a mixed-nutrient meal.
\end{abstract}

Methods In this cross-sectional study, participants with no family history of type 2 diabetes $\left(\mathrm{FH}^{-}\right)$for two generations $(\mathrm{n}=18)$, participants with positive family history of type 2 diabetes $(\mathrm{FH}+$; i.e. a parent with type 2 diabetes; $\mathrm{n}=16)$ and those with type 2 diabetes $(\mathrm{n}=12)$ underwent a mixed meal challenge (MMC). Metabolic responses (blood glucose, plasma insulin and indirect calorimetry) were measured before and during the MMC. Skeletal muscle large artery haemodynamics (2D and Doppler ultrasound, and Mobil-O-graph) and microvascular responses (contrast-enhanced ultrasound) were measured at baseline and $1 \mathrm{~h}$ post MMC.

Results Despite normal blood glucose concentrations, FH+ individuals displayed impaired metabolic flexibility (reduced ability to switch from fat to carbohydrate oxidation vs $\mathrm{FH}-$; $\mathrm{p}<0.05)$ during the MMC. The MMC increased forearm muscle microvascular blood volume in both the $\mathrm{FH}^{-}(1.3$-fold, $\mathrm{p}<0.01)$ and $\mathrm{FH}+(1.3$-fold, $\mathrm{p}<0.05)$ groups but not in participants with type 2 diabetes. However, the MMC increased MBF (1.9-fold, $p<0.01$ ), brachial artery diameter $(1.1$-fold, $\mathrm{p}<0.01)$ and brachial artery blood flow $(1.7$-fold, $\mathrm{p}<0.001)$ and reduced vascular resistance $(0.7$-fold, $\mathrm{p}<0.001)$ only in $\mathrm{FH}-$ participants, with these changes being absent in $\mathrm{FH}+$ and type 2 diabetes. Participants with type 2 diabetes displayed significantly higher vascular stiffness $(\mathrm{p}<0.001)$ compared with those in the $\mathrm{FH}-$ and $\mathrm{FH}+$ groups, however, vascular stiffness did not change during the MMC in any participant group. 
Conclusions/interpretation Normoglycaemic FH+ participants display impaired postprandial skeletal muscle macro- and microvascular responses, suggesting that poor vascular responses to a meal may contribute to their increased risk of type 2 diabetes. We conclude that vascular insulin resistance may be an early precursor to type 2 diabetes in humans, which can be revealed using a MMC.

Keywords Endothelium; Human; Imaging; Insulin sensitivity and resistance 


\section{Abbreviations}

AI

$\beta$

CEU

eNOS

$\mathrm{FH}-$

$\mathrm{FH}+$

$\mathrm{MBF}$

MBV

MMC

NOS

RER
Acoustic intensity

Microvascular flow velocity

Contrast-enhanced ultrasound

Endothelial nitric oxide synthase

No family history of type 2 diabetes

Positive family history of type 2 diabetes

Microvascular blood flow

Microvascular blood volume

Mixed meal challenge

Nitric oxide synthase

Respiratory exchange ratio 


\section{Research in context}

\section{What is already known about this subject?}

- People with a positive family history of type 2 diabetes $(\mathrm{FH}+$; i.e. a first degree relative with type 2 diabetes) are at higher risk of developing type 2 diabetes than the general population

- $\mathrm{FH}+$ people often have insulin resistance, with skeletal muscle being identified as a primary contributor

- The metabolic consequences of being FH+ are well established, however, the vascular outcomes in this at risk population are not known

\section{What is the key question?}

- Do apparently healthy people with a parent with type 2 diabetes have impaired postprandial skeletal muscle vascular responses?

\section{What are the new findings?}

- Despite having normal blood glucose concentrations, $\mathrm{FH}+$ individuals had impaired forearm muscle macro- and microvascular blood flow responses to a mixed meal challenge (MMC) similar to those with type 2 diabetes

- Impaired vascular reactivity is an early feature of being $\mathrm{FH}+$, which is identifiable via a MMC

\section{How might this impact on clinical practice in the foreseeable future?}

- Vascular insulin resistance is a key feature of $\mathrm{FH}+$ and may serve as a new therapeutic target for early intervention to prevent type 2 diabetes development 


\section{Introduction}

Despite new knowledge and advancements in medical care, the incidence of type 2 diabetes continues to rise along with its vascular complications [1]. The pathogenesis of type 2 diabetes is multifaceted, with insulin resistance recognised as an early feature in the development and progression of type 2 diabetes [2]. Having the capacity to identify insulin resistance early on in groups at risk of type 2 diabetes will provide insight into the early pathophysiology of type 2 diabetes and its complications, allowing targeted work using appropriate interventions.

It is well established that people with a first degree relative with type 2 diabetes are at higher risk of developing the disorder, with rates two- to sixfold greater than those without a family history [3]. Even in the presence of normal blood glucose levels, people with a positive family history of type 2 diabetes $(\mathrm{FH}+)$ often display whole-body insulin resistance [4], with skeletal muscle insulin resistance identified as a major contributor $[5,6]$. We have reported that normoglycaemic $\mathrm{FH}+$ adults have impaired metabolic flexibility to an oral glucose challenge (reduced ability to alter substrate oxidation postprandially) similar to those with established type 2 diabetes [7]. Although the metabolic consequences of $\mathrm{FH}+$ are well established, the vascular outcomes in this at risk population are unknown.

Skeletal muscle is an important tissue for postprandial glucose disposal $[8,9]$. Blood flow in skeletal muscle, in particular the microvasculature, plays an important role in this process [1015]. Physiological hyperinsulinaemia elicited by a hyperinsulinaemic-euglycaemic clamp or mixed meal challenge (MMC) stimulates both total-limb and microvascular blood flow (MBF) in the skeletal muscle of healthy humans [10-12]. Increased postprandial MBF is key for the delivery of glucose and insulin to myocytes [10-12]. Blunted skeletal muscle microvascular responses to insulin have been demonstrated in animal models of insulin resistance $[13,14]$ and type 2 diabetes [15], and in obese insulin resistant humans via insulin infusion and following a MMC $[10,12]$. This phenomenon is known as 'microvascular insulin resistance' 
and occurs early in the development of insulin resistance in animal models $[13,14,16]$, representing a role in the pathogenesis of type 2 diabetes. However, whether this microvascular pathology is present in apparently healthy 'at risk' humans is yet to be determined.

Therefore, the purpose of this study was to determine whether microvascular responses are impaired in apparently healthy people at risk for type 2 diabetes, and whether this could be revealed using a MMC. We assessed skeletal muscle micro- and macrovascular responses in normoglycaemic FH+ individuals, and compared their responses with both healthy people with no family history of type 2 diabetes ( $\left.\mathrm{FH}^{-}\right)$, and those with clinically diagnosed type 2 diabetes. It was hypothesised that the MMC would reveal step-wise impairments in muscle MBF across the type 2 diabetes continuum ( $\mathrm{FH}-\mathrm{vs} \mathrm{FH}+$ vs type 2 diabetes). 


\section{Methods}

Participants and screening This study was conducted at two sites and approved by the University of Tasmania and Deakin University Human Research Ethics Committees. All participants provided written informed consent. This study was conducted in accordance with the Declaration of Helsinki as revised in 2008, and procedures followed were in accordance with university guidelines.

Based on a priori power calculation, it was determined that 16 participants would be required to see a $30 \%$ difference in postprandial MBF in the healthy groups $(\alpha=0.05$, power $=80 \%)$. Eighteen healthy people with no family history of type 2 diabetes for two generations (neither parents nor grandparents with type 2 diabetes, $\mathrm{FH}^{-}$) and 16 healthy people with at least one parent with type 2 diabetes $(\mathrm{FH}+)$ completed the study. An additional 12 people with clinically diagnosed type 2 diabetes completed the study. Recruitment was done via community and university advertisement. Participants were included in the study if they were between 18 and 70 years old, had a BMI $>19 \mathrm{~kg} / \mathrm{m}^{2}$, and were stable weight for the past 3 months. Participants were excluded if they had a history of smoking, a clinical history of cardiovascular disease, myocardial infarction, stroke, uncontrolled BP (seated brachial BP >160/100 mmHg), pulmonary disease, peripheral artery disease, arthritis, skeletal muscle disease, severe liver disease or malignancy within the past 5 years. All participants attended a screening visit at the research facility, completed a medical questionnaire, and had height, weight and BP measured to determine eligibility. Participants also completed the International Physical Activity Questionnaire [17]. Participants were recruited and tested between August 2014 and October 2019. The study was a non-blinded, single-arm study, where participants completed a MMC.

Body composition Body composition was assessed using dual-energy x-ray absorptiometry (DEXA) (Lunar iDXA, GE Healthcare, Australia/New Zealand at Deakin University; Hologic 
Delphi densitometer, USA at the University of Tasmania). Total and trunk body fat were determined for all participants.

Clinic visits Participants arrived at the testing facility after an overnight fast and having refrained from strenuous exercise and alcohol consumption for $48 \mathrm{~h}$. Medications for type 2 diabetes were stopped for $48 \mathrm{~h}$ prior to testing. Participants lay supine while a cannula was placed in the antecubital vein of the left arm for blood sampling and infusion of a contrast agent.

MMC A liquid MMC comprising $1254 \mathrm{~kJ}$ (53\% carbohydrate, 29\% protein and $15 \%$ fat) was given to the participants and was consumed within a 5 min time period. Blood was sampled every 15-30 min over $2 \mathrm{~h}$ following ingestion of the meal. Blood glucose and plasma insulin AUC were both calculated using the trapezoidal rule.

Blood analysis Fasting glucose, $\mathrm{HbA}_{1 \mathrm{c}}$, total cholesterol, triacylglycerol, $\mathrm{HDL}$-cholesterol and LDL-cholesterol were measured at an accredited pathology laboratory (Australian Clinical Labs, Australia for the Deakin University site; Royal Hobart Hospital, Australia for the University of Tasmania site). Blood glucose was measured by an automated analyser (ABL800 FLEX blood gas analyser, Radiometer Medical, Denmark at the Deakin University site; Yellow Springs Instruments, USA at the University of Tasmania site), and plasma insulin measured using an enzyme-linked immunosorbent assay (ALPCO, Salem, NH, USA).

Indirect calorimetry for assessment of metabolic flexibility Participants wore a silicon facemask attached to a metabolic cart (Quark RMR Cosmed, Italy for the Deakin University site; MasterScreen CPX, CareFusion, Germany for the University of Tasmania site) for 20 min at baseline and for $55 \mathrm{~min}$ following ingestion of the MMC to collect and analyse expired gases. The metabolic cart was calibrated using room air and a gas mixture of a known $\mathrm{O}_{2}$ and $\mathrm{CO}_{2}$ concentration before each clinical testing visit. Breath-by-breath data were collected and 
analysed in 5 min blocks from which the respiratory exchange ratio (RER) was determined. Metabolic flexibility was calculated as the change in RER (from baseline) AUC ( $\triangle$ RER AUC).

Skeletal muscle MBF Contrast-enhanced ultrasound (CEU) was used to determine microvascular responses of the right forearm flexor group. An L9-3 linear array transducer interfaced to an ultrasound machine was used (iU22; Philips Healthcare, Australia - same for both sites). Microbubbles (1.5 ml, Definity, Lantheus Medical Imaging, Australia) were diluted into $30 \mathrm{ml}$ of saline $(154 \mathrm{mmol} / \mathrm{l} \mathrm{NaCl})$ and continuously infused intravenously for CEU imaging. Microbubbles were infused at 120-160 ml/hr (based on participant's body weight and degree of tissue opacification). Once the systemic concentration of microbubbles reached steady state ( $\sim 5 \mathrm{~min})$, a high-energy pulse of ultrasound (mechanical index 1.3) was transmitted to destroy microbubbles in the selected region of imaging (deep flexor muscle group). Rate of reperfusion (mechanical index 0.11 for continuous imaging) into the microvasculature of the muscle was measured in real time at baseline and repeated 60 min following the MMC. Microbubble infusion, gain, depth and focus were optimised for each participant and kept identical between baseline and 60 min measurements. The arterial concentration of microbubbles was determined by imaging the brachial artery at a submaximal concentration $(30 \mathrm{ml} / \mathrm{h})$ and used to correct for any changes in blood pool concentration of microbubbles between participants.

Images were background subtracted to eliminate signal from larger blood vessels that had greater velocities and tissue per se. Background-subtracted acoustic intensity (AI) vs time was fitted to the following equation: $y=\mathrm{A}\left(1-\mathrm{e}^{-\beta(t-t b)}\right)$, where $\mathrm{y}$ is $\mathrm{AI}$ at time $t, t b$ is background time $(0.5 \mathrm{~s}), \mathrm{A}$ is $\mathrm{AI}$ at the plateau of the curve (a measure of microvascular blood volume [MBV]), $\beta$ is the time $\kappa$ (a measure of microvascular refilling rate) and e is Euler's number. MBF was determined by $A \times \beta$. An example of an ultrasound image and its corresponding curve fit has been provided (electronic supplementary material [ESM] Fig. 1). 
Brachial and large artery haemodynamics Brachial artery measures were taken $\sim 5-10 \mathrm{~cm}$ proximal to the antecubital fold with an L12-5 linear array transducer. Brachial artery diameter was measured in triplicate using 2D imaging of the longitudinal artery. Velocity was determined using pulse wave Doppler, measured by automated tracing software, and the values averaged over approximately 10-12 heartbeats. Diameter and velocity values were used to determine brachial artery blood flow at baseline and 60 min post-ingestion of the MMC.

All participants were fitted with a Mobil-O-Graph monitor (IEM, Germany), validated to estimate central and brachial BP, vascular stiffness and augmentation index [18]. Central aortic pulse wave velocity was also estimated using this device by analysis of oscillometric brachial cuff waveforms [19]. Readings were taken at baseline and at $60 \mathrm{~min}$ post-ingestion of the MMC. Augmentation index was calculated from the central pressure waveform and normalised to a heart rate of 75 beats per min (bpm). Since augmentation index is associated with height, we also indexed this variable to the participant's height. Forearm vascular resistance was calculated by dividing mean arterial pressure $(\mathrm{mmHg})$ by total brachial arterial blood flow $(\mathrm{ml} / \mathrm{min})$.

Statistical methods Data are presented as the means \pm SEM after testing for normality using the Kolmogorov-Smirnov test. Continuous measurements in tables are also expressed as a median and IQR. Categorical variables in tables are reported as numbers and percentages. A one-way ANOVA was used to compare differences between groups. For categorical variables, a Fisher's exact test was performed. Comparisons of multiple means were examined using a two-way repeated measures ANOVA (group $\times$ time) followed by a Student-Neuman-Keuls post hoc test. Planned contrast analysis of the baseline and postprandial time points were conducted using a Student-Neuman-Keuls test if there was a main effect for group or time. If data were not normally distributed, the data were log transformed for analysis only. If data 
were missing, the participant for that particular measurement was omitted. Statistics were performed using SigmaPlot (Systat Software, USA). A value of $\mathrm{p}<0.05$ was considered as statistically significant.

\section{Results}

Participants Of the 53 participants screened, three were not eligible, two were lost to followup and two dropped out, resulting in 46 participants completing the study. The participants who were not eligible included one $\mathrm{FH}-$ participant who was underweight $\left(\mathrm{BMI}<19 \mathrm{~kg} / \mathrm{m}^{2}\right.$ ), one individual with type 2 diabetes but normal fasting blood glucose and $\mathrm{HbA}_{1 \mathrm{c}}$ levels, and one individual with type 2 diabetes with a previous reaction to Definity contrast agent. Two participants were lost to follow-up (one $\mathrm{FH}+$ and one with type 2 diabetes) and two dropped out (one $\mathrm{FH}^{-}$and one $\mathrm{FH}+$ ) due to difficulties with venous cannulation. Equipment malfunction resulted in loss of participant data for metabolic flexibility (one FH-), CEU (one $\mathrm{FH}^{-}$), brachial artery (one $\mathrm{FH}^{-}$) and vascular resistance and stiffness (one $\mathrm{FH}-$ and one $\mathrm{FH}+$ ).

Participant characteristics Blood analysis and anthropometric characteristics are summarised in Table 1. FH- and $\mathrm{FH}+$ participants had similar age, fasting clinical chemistries (blood glucose, $\mathrm{HbA}_{1 \mathrm{c}}$, plasma insulin, plasma lipids), HOMA-IR, QUICKI and BMI. FH+ individuals had greater total body (\%) and trunk fat (\%) than $\mathrm{FH}-$ individuals.

As expected, people with type 2 diabetes displayed greater body weight, BMI, fasting glucose, $\mathrm{HbA}_{1 \mathrm{c}}$, plasma insulin, HOMA-IR and triacylglycerol and lower QUICKI than $\mathrm{FH}-$ and $\mathrm{FH}+$ individuals. In addition, people with type 2 diabetes had elevated central systolic BP (cSBP), total body (\%) and trunk fat (\%) (Table 1) and medication use (ESM Table 1) compared with $\mathrm{FH}-$ and $\mathrm{FH}+$ participants. Self-reported physical activity levels (moderate and vigorous combined) were not statistically different between groups (Table 1). 
Metabolic responses to the MMC Blood glucose levels increased over time in all groups following the MMC (Fig. 1a). The $2 \mathrm{~h}$ glucose AUC following the MMC was significantly greater $(\mathrm{p}<0.001)$ in participants with type 2 diabetes compared with $\mathrm{FH}-$ and $\mathrm{FH}+($ Fig. $1 \mathrm{~b})$, whereas the AUC did not differ between $\mathrm{FH}-$ and $\mathrm{FH}+$ (Fig. 1b).

Plasma insulin levels increased over time in all groups in response to the MMC (Fig. 1c). There was a significant interaction (group $\times$ time, $\mathrm{p}=0.006$ ) for the plasma insulin time course; however, the post hoc did not reveal any significant differences at any time point between groups. The insulin $2 \mathrm{~h}$ AUC was not different between groups (Fig. 1d).

RER increased from baseline in response to the $\mathrm{MMC}$ in the $\mathrm{FH}-$ and $\mathrm{FH}+$ groups but not in the type 2 diabetes group (Fig. 1e). There was a significant interaction (group $\times$ time, $p=0.002$ ) for the RER time course; however, the post hoc did not reveal any significant differences at any time point between groups. Metabolic flexibility ( $\triangle$ RER AUC) was significantly blunted in both type 2 diabetes and the $\mathrm{FH}+$ groups compared with the $\mathrm{FH}-$ group in response to the MMC (Fig. 1f).

Skeletal muscle microvascular responses to the MMC Forearm MBV increased significantly from baseline in response to the MMC in both $\mathrm{FH}-(\mathrm{p}<0.01)$ and $\mathrm{FH}+(\mathrm{p}<0.05)$ groups; however, this response was absent in the type 2 diabetes group (Fig. 2a). Skeletal muscle $\beta$ (microvascular flow velocity) did not change in response to the MMC and did not differ between groups (Fig. 2b). The FH- group had a significantly elevated $(p<0.01)$ forearm muscle MBF response to the MMC (Fig. 2c), which was blunted in both $\mathrm{FH}+$ and type 2 diabetes. $\mathrm{FH}+$ participants had a significantly lower \% change in postprandial MBF (but not MBV or $\beta$ individually) compared with FH- participants (ESM Fig. 2).

Brachial artery responses to the MMC Brachial artery diameter increased significantly in $\mathrm{FH}-$ participants $(\mathrm{p}<0.01)$ in response to the MMC; however, no changes were observed in the 
$\mathrm{FH}+$ and type 2 diabetes groups (Fig. 3a). Brachial artery flow velocity did not change in response to the MMC and did not differ between groups (Fig. 3b). Brachial artery blood flow increased in response to the $\mathrm{MMC}$ in $\mathrm{FH}^{-}(\mathrm{p}<0.001)$, but not $\mathrm{FH}+$ or type 2 diabetes participants (Fig. 3c).

Vascular resistance and stiffness Resting forearm vascular resistance (mean arterial BP divided by brachial blood flow) was not different between groups; however, the FH- group had a significant decrease $(\mathrm{p}<0.001)$ post-MMC which was absent in the $\mathrm{FH}+$ and type 2 diabetes groups (Fig. 4a). FH+ individuals had significantly greater forearm vascular resistance than $\mathrm{FH}-$ following the MMC ( $\mathrm{p}<0.05)$ (Fig. 4a).

Pulse wave velocity (vascular stiffness) did not change in response to the MMC across any of the participant groups (Fig. 4b). However, participants with type 2 diabetes had higher pulse wave velocity at rest and following the MMC than both $\mathrm{FH}^{-}(\mathrm{p}<0.001)$ and $\mathrm{FH}+(\mathrm{p}<0.001)$ groups (Fig. 4b).

Augmentation index was not different at baseline and did not change in response to the MMC across any of the participant groups (Fig. 4c).

Exploratory analyses Our study was not designed or powered to assess impact of sex, body composition and phase of menstrual cycle on outcomes. We have performed an exploratory analysis to address these confounders by excluding all female participants and those male participants with very low body fat $(<15 \%)$ and show that when $\mathrm{FH}-$ and $\mathrm{FH}+$ male participants had similar height, weight, $\mathrm{BMI}$ and $\%$ body fat, $\mathrm{FH}+$ participants still display an impairment in postprandial MBF, brachial flow, forearm vascular resistance and metabolic flexibility (ESM Table 2). 


\section{Discussion}

Our study demonstrates for the first time that otherwise healthy $\mathrm{FH}+$ people display impaired vascular haemodynamic responses to a mixed-nutrient meal. These findings are important as vascular responses to meal ingestion, in particular increased muscle MBF, are critical for prevention of cardiometabolic disease. We conclude that vascular impairments may be an early precursor to type 2 diabetes in humans, which can be revealed in the postprandial state following mixed meal ingestion.

Skeletal muscle is an important tissue for postprandial glucose disposal $[8,9]$. Skeletal muscle glucose uptake and utilisation occur via a combination of an increase in blood glucose concentration (mass action effect), and a rise in endogenous insulin levels enhancing glucose uptake into tissues from the bloodstream [8]. Regulation of muscle blood flow by insulin is an important physiological process as it controls the rate of glucose and insulin delivery to the myocyte [20,21]. In skeletal muscle of healthy people, physiological hyperinsulinaemia, either during a hyperinsulinaemic-euglycaemic clamp or elicited via mixed meal ingestion, stimulates both total-limb blood flow (macrovascular blood flow) and MBF [10-12]. Blunted skeletal muscle microvascular responses to insulin have been demonstrated in animal models of insulin resistance $[13,14]$ and type 2 diabetes [15]. The impaired microvascular responses to insulin contribute to muscle insulin resistance and occur before defects in large artery haemodynamics $[13,14]$. Using animal models, others have demonstrated that microvascular insulin resistance occurs early (3 days following high fat feeding) and precedes whole-body insulin resistance ( 7 days) and impairments in large artery vasodilation to acetylcholine (28 days) in rats [22]. Here we extend these findings and demonstrate an impaired MBF response in apparently healthy (normoglycaemic) $\mathrm{FH}+$ individuals in response to a MMC.

It is well established that $\mathrm{FH}+$ individuals are at higher risk of developing type 2 diabetes than those without a family history of diabetes [3]. In particular, $\mathrm{FH}+$ people often display skeletal 
muscle insulin resistance as a major contributor of disease progression $[5,6]$. The blunted metabolic flexibility in our $\mathrm{FH}+$ group indicates altered whole-body metabolism in these people, despite normal postprandial blood glucose and plasma insulin levels when compared with $\mathrm{FH}-$ individuals. Normoglycaemic $\mathrm{FH}+$ individuals are reported to have impaired metabolic flexibility in response to oral glucose loading [7]. We observed similar impairments in metabolic flexibility in $\mathrm{FH}+$ individuals when using a more physiologically relevant postprandial challenge containing fat and protein, which are not present in pure glucose loads [7]. We cannot ascertain the fate of glucose after the MMC without the addition of isotopic tracers, measures of muscle glucose disposal and glycogen content. However, metabolic flexibility is positively associated with whole-body glucose disposal $(r=0.65, p<0.0001)[23]$. In the present study, we present novel findings to suggest that loss of skeletal muscle microvascular insulin sensitivity alongside impaired metabolic flexibility may occur before the development of whole-body insulin resistance. This finding is in agreement and adds mechanistic rationale to other studies showing impaired forearm muscle glucose uptake in $\mathrm{FH}+$ individuals during a MMC [24].

In our study, MBF impairment in the $\mathrm{FH}+$ group was observed despite MBV (capillary recruitment) increasing to a similar extent as in the $\mathrm{FH}-$ group, highlighting that dilation of pre-capillary arterioles remain intact in our cohort of $\mathrm{FH}+$ (but not in type 2 diabetes), in the postprandial state. Insulin (hyperinsulinaemic-euglycaemic clamp) increases MBV in skeletal muscle in rats and humans which positively influences glucose disposal [25-27]. Other studies demonstrate that velocity influences insulin-stimulated glucose disposal (their experimental paradigm does not allow for insulin to increase MBV due to full capillary recruitment in their experimental model) [28]. As such, there is a growing body of evidence that both volume and velocity and, therefore, $\mathrm{MBF}$ are important for glucose disposal in skeletal muscle. Improvements in MBF after exercise training in people with type 2 diabetes are intimately 
linked with improved glucose regulation [29]. This suggests that the flow velocity within the microcirculation plays an important role in influencing MBF following a MMC.

Postprandial brachial artery dilation (measured as vessel diameter) and blood flow was increased in $\mathrm{FH}-$, but absent in people with $\mathrm{FH}+$ and type 2 diabetes. These data may indicate endothelial dysfunction in $\mathrm{FH}+$, which can manifest early on and is sustained across the type 2 diabetes continuum. In support, other studies have shown that $\mathrm{FH}+$ individuals have impaired large artery endothelial function as assessed by endothelial-mediated vasodilators or flowmediated dilation [4, 30-32]. Our findings of impaired brachial artery responses are consistent with other data showing similar impairments in forearm muscle blood flow in the postprandial state in FH+ individuals and those with type 2 diabetes [24]. Lambadiari et al demonstrated that the macrovascular impairment influenced postprandial glucose disposal (with forearm muscle blood flow positively correlating with muscle glucose disposal) [24]. However, that study did not assess skeletal muscle specific MBF which is important because it is the microvasculature that controls glucose and insulin delivery to the myocyte $[20,25,33,34]$ because not all vasodilators that augment large artery blood flow concomitantly increase glucose disposal to muscle. Methacholine and sodium nitroprusside can each increase large artery blood flow but can have opposing effects on muscle insulin-mediated glucose disposal $[35,36]$. Large artery blood flow can be separated from flow changes within the microcirculation. For example, vasodilation with methacholine during a hyperinsulinaemiceuglycaemic clamp in rats augments insulin-mediated microvascular perfusion and muscle glucose uptake, whereas a similar degree of vasodilation with bradykinin has the opposite effect [37]. Adrenaline (epinephrine) stimulates total-limb blood flow without altering muscle microvascular perfusion $[38,39]$ providing further evidence that measuring large artery blood flow does not always dictate changes at the microvascular level. 
Although the mechanism for postprandial-mediated vasodilation is not yet fully understood, it has been consistently shown that insulin (hyperinsulinaemic-euglycaemic clamp) stimulates brachial artery blood flow and MBF via a nitric oxide synthase (NOS)-dependent process [25, 40, 41] with endothelial NOS (eNOS) being the major isoform [16, 42]. Postprandial endothelial dysfunction can be restored with L-arginine supplementation (a precursor to nitric oxide) in overweight individuals low in L-arginine [43] suggesting that ingestion of food stimulates blood flow via a NOS-dependent process. Cultured endothelial cells taken from umbilical cords of healthy FH+ newborns have impaired expression of eNOS and low rates of nitric oxide synthesis [44]. Therefore, it is perhaps not surprising that $\mathrm{FH}+$ individuals, even those who are apparently healthy, have impaired postprandial stimulated macrovascular blood flow and MBF. However, further work linking NOS defects with poor postprandial muscle MBF needs to be performed.

In support of previous research, the type 2 diabetes group displayed higher BP and vascular stiffness (higher pulse wave velocity) than $\mathrm{FH}-$ and $\mathrm{FH}+$ groups [45]. However, we did not observe any differences in vascular stiffness between $\mathrm{FH}^{-}$and $\mathrm{FH}+$ groups which is in contrast to others who have demonstrated greater vascular stiffness in $\mathrm{FH}+[46,47]$. These major differences are likely due to previous studies recruiting cohorts of $\mathrm{FH}+$ with a more advanced form of insulin resistance (higher HOMA-IR and/or higher insulin secretion to a postprandial challenge). Despite normal BP and vascular compliance, we demonstrate that FH+ individuals have impaired brachial blood flow and forearm vascular resistance compared with $\mathrm{FH}^{-}$. This may indicate that the development of arterial stiffness (which is likely to reflect structural changes to the circulatory system) takes place after the establishment of endothelial dysfunction, and that these structural vascular derangements are distinct in the pathogenesis of insulin resistance and type 2 diabetes. 
Several limitations are acknowledged in this study. First, the participants with type 2 diabetes were older than those in the $\mathrm{FH}-$ and $\mathrm{FH}+$ groups. However, the primary aim of the study was to compare the metabolic and vascular responses in age-matched $\mathrm{FH}-$ and $\mathrm{FH}+$ individuals, whereas the type 2 diabetes group was recruited as a negative control. Therefore, recruiting a younger cohort of participants with type 2 diabetes would not have impacted the main findings or conclusions of the study. Second, although healthy $\mathrm{FH}-$ and $\mathrm{FH}+$ participants were matched for BMI, the FH+ group had significantly greater amounts of total and truncal body fat, which may contribute to their vascular insulin resistance. We also acknowledge the $\mathrm{FH}+$ group had a greater proportion of female participants than the $\mathrm{FH}^{-}$group. However, our exploratory analysis (ESM Table 2) showed that sex and differences in body composition between the $\mathrm{FH}-$ and $\mathrm{FH}+$ groups did not impact on the outcomes or the overall interpretation of the current study. Understanding why $\mathrm{FH}+$ individuals have impaired postprandial skeletal muscle vascular actions is important to follow-up.

Conclusion Postprandial vascular insulin resistance is an early pathophysiological feature of insulin resistance even in the presence of normoglycaemia. A loss of vascular responsiveness (in particular MBF) that manifests after each meal in people with insulin resistance may be a mechanism that, over time, contributes to worsening of insulin resistance, hyperglycaemia and type 2 diabetes development. Correcting this microvascular defect may be an early intervention strategy in people at increased risk of type 2 diabetes such as those with a family history. 
Acknowledgements The authors would like to thank T. Marwick (Baker Heart and Diabetes Institute, Melbourne, VIC, Australia) for his intellectual input and for providing feedback on the manuscript. They would also like to thank K. Negishi (University of Sydney, Camperdown, NSW, Australia) and A. Garnham and G. Kaur (both Deakin University, Geelong, VIC, Australia) for help with i.v. cannulations. They would also like to thank K. Squibb (University of Tasmania, Hobart, TAS, Australia) for her assistance with dual-energy x-ray absorptiometry (DEXA).

Data availability Data generated for the current study are available on reasonable request from the corresponding author in the form of excel spreadsheets.

Funding This work was supported by the Royal Hobart Hospital Research Foundation (2016) and the Deakin University Institute for Physical Activity and Nutrition (2018) grants. LP is supported by an NHMRC \& National Heart Foundation Fellowship (APP1157930).

Authors' relationships and activities The authors declare that there are no relationships or activities that might bias, or be perceived to bias, their work.

Contribution statement RDR and MAK were responsible for the conception and design of the research. RDR, KR-T and MAK performed the experiments. TG, DH, ACB, LP, JES and DP assisted in the data collection. KR-T and MAK performed the statistical analyses. All authors interpreted the data. KR-T drafted the manuscript and MAK and RDR provided the first edits. All authors revised and approved the final manuscript. MAK is the guarantor of this work. 


\section{References}

[1] Morrish NJ, Wang SL, Stevens LK, Fuller JH, Keen H (2001) Mortality and causes of death in the WHO Multinational Study of Vascular Disease in Diabetes. Diabetologia 44(Suppl 2): S14-21

[2] Ramlo-Halsted BA, Edelman SV (1999) The natural history of type 2 diabetes. Implications for clinical practice. Prim Care 26: 771-789

[3] Meigs JB, Cupples LA, Wilson PW (2000) Parental transmission of type 2 diabetes: the Framingham Offspring Study. Diabetes 49: 2201-2207

[4] Tesauro M, Rizza S, Iantorno M, et al. (2007) Vascular, metabolic, and inflammatory abnormalities in normoglycemic offspring of patients with type 2 diabetes mellitus. Metabolism 56: 413-419

[5] Gulli G, Ferrannini E, Stern M, Haffner S, DeFronzo RA (1992) The metabolic profile of NIDDM is fully established in glucose-tolerant offspring of two MexicanAmerican NIDDM parents. Diabetes 41: 1575-1586

[6] Petersen KF, Dufour S, Befroy D, Garcia R, Shulman GI (2004) Impaired mitochondrial activity in the insulin-resistant offspring of patients with type 2 diabetes. $\mathrm{N}$ Engl J Med 350: 664-671

[7] Russell RD, Kraemer RR, Nelson AG (2013) Metabolic dysfunction in diabetic offspring: deviations in metabolic flexibility. Med Sci Sports Exerc 45: 8-15 [8] Wilcox G (2005) Insulin and insulin resistance. Clin Biochem Rev 26: 19-39

[9] Thiebaud D, Jacot E, DeFronzo RA, Maeder E, Jequier E, Felber JP (1982) The effect of graded doses of insulin on total glucose uptake, glucose oxidation, and glucose storage in man. Diabetes 31: 957-963 
[10] Clerk LH, Vincent MA, Jahn LA, Liu Z, Lindner JR, Barrett EJ (2006) Obesity blunts insulin-mediated microvascular recruitment in human forearm muscle. Diabetes 55: 14361442

[11] Vincent MA, Clerk LH, Lindner JR, et al. (2006) Mixed meal and light exercise each recruit muscle capillaries in healthy humans. Am J Physiol Endocrinol Metab 290: E1191E1197

[12] Keske MA, Clerk LH, Price WJ, Jahn LA, Barrett EJ (2009) Obesity blunts microvascular recruitment in human forearm muscle after a mixed meal. Diabetes Care 32: $1672-1677$

[13] Premilovac D, Bradley EA, Ng HL, Richards SM, Rattigan S, Keske MA (2013) Muscle insulin resistance resulting from impaired microvascular insulin sensitivity in Sprague Dawley rats. Cardiovasc Res 98: 28-36

[14] Premilovac D, Richards SM, Rattigan S, Keske MA (2014) A vascular mechanism for high-sodium-induced insulin resistance in rats. Diabetologia 57: 2586-2595

[15] Clerk LH, Vincent MA, Barrett E, Lankford MF, Lindner JR (2007) Skeletal muscle capillary responses to insulin are abnormal in late-stage diabetes and are restored by angiotensin converting enzyme inhibition. Am J Physiol Endocrinol Metab 293: E1804E1809

[16] Kubota T, Kubota N, Kumagai H, et al. (2011) Impaired insulin signaling in endothelial cells reduces insulin-induced glucose uptake by skeletal muscle. Cell Metab 13: 294-307

[17] International Physical Activity Questionnaire (IPAQ); [accessed on 20th April 2014] Available online: https://sites.google.com/site/theipaq/home

[18] Weber T, Wassertheurer S, Rammer M, et al. (2011) Validation of a brachial cuffbased method for estimating central systolic blood pressure. Hypertension 58: 825-832 
[19] Hametner B, Wassertheurer S, Kropf J, Mayer C, Eber B, Weber T (2013)

Oscillometric estimation of aortic pulse wave velocity: comparison with intra-aortic catheter measurements. Blood Press Monit 18: 173-176

[20] Roberts-Thomson KM, Betik AC, Premilovac D, et al. (2020) Postprandial microvascular blood flow in skeletal muscle: Similarities and disparities to the hyperinsulinaemic-euglycaemic clamp. Clin Exp Pharmacol Physiol 47: 725-737

[21] Barrett EJ, Eggleston EM, Inyard AC, et al. (2009) The vascular actions of insulin control its delivery to muscle and regulate the rate-limiting step in skeletal muscle insulin action. Diabetologia 52: 752-764

[22] Zhao L, Fu Z, Wu J, et al. (2015) Inflammation-induced microvascular insulin resistance is an early event in diet-induced obesity. Clin Sci 129: 1025-1036

[23] Galgani JE, Heilbronn LK, Azuma K, et al. (2008) Metabolic flexibility in response to glucose is not impaired in people with type 2 diabetes after controlling for glucose disposal rate. Diabetes 57: 841-845

[24] Lambadiari V, Mitrou P, Maratou E, Raptis A, Raptis SA, Dimitriadis G (2012) Increases in muscle blood flow after a mixed meal are impaired at all stages of type 2 diabetes. Clin Endocrinol 76: 825-830

[25] Vincent MA, Clerk LH, Lindner JR, et al. (2004) Microvascular recruitment is an early insulin effect that regulates skeletal muscle glucose uptake in vivo. Diabetes 53: 14181423

[26] Zhang L, Vincent MA, Richards SM, et al. (2004) Insulin sensitivity of muscle capillary recruitment in vivo. Diabetes 53: 447-453

[27] Eggleston EM, Jahn LA, Barrett EJ (2007) Hyperinsulinemia rapidly increases human muscle microvascular perfusion but fails to increase muscle insulin clearance: evidence that a saturable process mediates muscle insulin uptake. Diabetes 56: 2958-2963 
[28] McClatchey PM, Williams IM, Xu Z, et al. (2019) Perfusion Controls Muscle

Glucose Uptake by Altering the Rate of Glucose Dispersion In Vivo. Am J Physiol

Endocrinol Metab 317: E1022-E1036

[29] Russell RD, Hu D, Greenaway T, et al. (2017) Skeletal Muscle Microvascular-Linked Improvements in Glycemic Control From Resistance Training in Individuals With Type 2

Diabetes. Diabetes Care 40: 1256-1263

[30] Balletshofer BM, Rittig K, Enderle MD, et al. (2000) Endothelial dysfunction is detectable in young normotensive first-degree relatives of subjects with type 2 diabetes in association with insulin resistance. Circulation 101: 1780-1784

[31] Sonne MP, Hojbjerre L, Alibegovic AA, Vaag A, Stallknecht B, Dela F (2009) Impaired endothelial function and insulin action in first-degree relatives of patients with type 2 diabetes mellitus. Metabolism 58: 93-101

[32] Goldfine AB, Beckman JA, Betensky RA, et al. (2006) Family history of diabetes is a major determinant of endothelial function. J Am Coll Cardiol 47: 2456-2461

[33] Clark MG, Wallis MG, Barrett EJ, et al. (2003) Blood flow and muscle metabolism: a focus on insulin action. Am J Physiol Endocrinol Metab 284: E241-258

[34] Vincent MA, Dawson D, Clark AD, et al. (2002) Skeletal muscle microvascular recruitment by physiological hyperinsulinemia precedes increases in total blood flow.

Diabetes 51: 42-48

[35] Baron AD, Tarshoby M, Hook G, et al. (2000) Interaction between insulin sensitivity and muscle perfusion on glucose uptake in human skeletal muscle: evidence for capillary recruitment. Diabetes 49: 768-774

[36] Natali A, Quinones Galvan A, Pecori N, Sanna G, Toschi E, Ferrannini E (1998) Vasodilation with sodium nitroprusside does not improve insulin action in essential hypertension. Hypertension 31: 632-636 
[37] Mahajan H, Richards SM, Rattigan S, Clark MG (2004) Local methacholine but not bradykinin potentiates insulin-mediated glucose uptake in muscle in vivo by augmenting capillary recruitment. Diabetologia 47: 2226-2234

[38] Rattigan S, Clark MG, Barrett EJ (1997) Hemodynamic actions of insulin in rat skeletal muscle: evidence for capillary recruitment. Diabetes 46: 1381-1388

[39] Clark AD, Barrett EJ, Rattigan S, Wallis MG, Clark MG (2001) Insulin stimulates laser Doppler signal by rat muscle in vivo, consistent with nutritive flow recruitment. Clin Sci 100: $283-290$

[40] Vincent MA, Barrett EJ, Lindner JR, Clark MG, Rattigan S (2003) Inhibiting NOS blocks microvascular recruitment and blunts muscle glucose uptake in response to insulin. Am J Physiol Endocrinol Metab 285: E123-E129

[41] Bradley EA, Richards SM, Keske MA, Rattigan S (2013) Local NOS inhibition impairs vascular and metabolic actions of insulin in rat hindleg muscle in vivo. Am J Physiol Endocrinol Metab 305: E745-750

[42] Vincent MA, Montagnani M, Quon MJ (2003) Molecular and physiologic actions of insulin related to production of nitric oxide in vascular endothelium. Current Diabetes Reports 3: 279-288

[43] Deveaux A, Pham I, West SG, et al. (2016) 1-Arginine Supplementation Alleviates Postprandial Endothelial Dysfunction When Baseline Fasting Plasma Arginine Concentration Is Low: A Randomized Controlled Trial in Healthy Overweight Adults with Cardiometabolic Risk Factors. J Nutr 146: 1330-1340

[44] Alvarado-Vasquez N, Zapata E, Alcazar-Leyva S, Masso F, Montano LF (2007) Reduced NO synthesis and eNOS mRNA expression in endothelial cells from newborns with a strong family history of type 2 diabetes. Diabetes Metab Res Rev 23: 559-566 
[45] Schultz MG, Climie RE, Nikolic SB, Ahuja KD, Sharman JE (2013) Persistent elevation of central pulse pressure during postural stress in patients with type 2 diabetes mellitus. J Hum Hypertens 27: 437-444

[46] Ikonomidis I, Lambadiari V, Pavlidis G, et al. (2015) Insulin resistance and acute glucose changes determine arterial elastic properties and coronary flow reserve in dysglycaemic and first-degree relatives of diabetic patients. Atherosclerosis 241: 455-462 [47] Scuteri A, Tesauro M, Rizza S, et al. (2008) Endothelial function and arterial stiffness in normotensive normoglycemic first-degree relatives of diabetic patients are independent of the metabolic syndrome. Nutr Metab Cardiovasc Dis 18: 349-356 
Table 1 Participant characteristics

\begin{tabular}{|c|c|c|c|}
\hline Characteristic & FH- & $\mathrm{FH}+$ & Type 2 diabetes \\
\hline Sex, male/female & $13 / 5$ & $8 / 8$ & $7 / 5$ \\
\hline \multicolumn{4}{|l|}{ Age, years } \\
\hline Mean \pm SEM & $40 \pm 4$ & $39 \pm 3$ & $56 \pm 2^{\S, \emptyset}$ \\
\hline Median (IQR) & $41(25-57)$ & $40(31-47)$ & $58(53-60)$ \\
\hline \multicolumn{4}{|l|}{ Diabetes duration, years } \\
\hline Mean \pm SEM & - & - & $8 \pm 1$ \\
\hline Median (IQR) & - & - & $8(4-12)$ \\
\hline \multicolumn{4}{|l|}{ Height, cm } \\
\hline Mean \pm SEM & $176 \pm 2$ & $167 \pm 3^{\S}$ & $168 \pm 2^{\S}$ \\
\hline Median (IQR) & $179(167-183)$ & $168(159-176)$ & $169(160-176)$ \\
\hline \multicolumn{4}{|l|}{ Weight, kg } \\
\hline Mean \pm SEM & $76.5 \pm 2.5$ & $72.7 \pm 3.2$ & $89.3 \pm 5.2^{\S, \emptyset}$ \\
\hline Median (IQR) & $74.2(69.6-87.6)$ & $76.5(64.3-81.1)$ & $90.5(74.3-108.0)$ \\
\hline \multicolumn{4}{|l|}{ BMI, $\mathrm{kg} / \mathrm{m}^{2}$} \\
\hline Mean \pm SEM & $24.7 \pm 0.7$ & $25.9 \pm 0.8$ & $31.6 \pm 1.6^{\S, \pi}$ \\
\hline Median (IQR) & $24.6(22.4-26.1)$ & $25.9(24.0-28.3)$ & $31.6(26.6-34.5)$ \\
\hline \multicolumn{4}{|l|}{ Total fat, $\%$} \\
\hline Mean \pm SEM & $22.8 \pm 2.0$ & $30.7 \pm 1.8^{\S}$ & $33.3 \pm 2.8^{\S}$ \\
\hline Median (IQR) & $20.2(16.4-28.1)$ & $30.3(24.6-35.4)$ & $32.4(25.6-40.7)$ \\
\hline \multicolumn{4}{|l|}{ Trunk fat, $\%$} \\
\hline Mean \pm SEM & $22.5 \pm 1.9$ & $30.9 \pm 1.9^{\S}$ & $36.1 \pm 2.6^{\S}$ \\
\hline Median (IQR) & $21.2(16.5-29.4)$ & $30.8(24.3-35.9)$ & $36.1(29.2-45.4)$ \\
\hline \multicolumn{4}{|l|}{ Physical activity, $\mathrm{h} /$ week $^{\mathrm{a}}$} \\
\hline Mean \pm SEM & $7.0 \pm 1.0$ & $4.2 \pm 1.5$ & $4.4 \pm 1.9$ \\
\hline Median (IQR) & $8.1(3.9-9.9)$ & $2.7(1.4-5.4)$ & $1.7(0.0-7.8)$ \\
\hline \multicolumn{4}{|l|}{ Fasting glucose, $\mathrm{mmol} / \mathrm{l}$} \\
\hline Mean \pm SEM & $4.7 \pm 0.1$ & $4.6 \pm 0.2$ & $10.1 \pm 10.9^{\S, \uparrow}$ \\
\hline Median (IQR) & $4.7(4.3-5.0)$ & $4.8(4.2-5.1)$ & $9.9(7.2-12.4)$ \\
\hline \multicolumn{4}{|l|}{$\mathrm{HbA}_{1 \mathrm{c}}, \mathrm{mmol} / \mathrm{mol}$} \\
\hline Mean \pm SEM & $35 \pm 1$ & $34 \pm 1$ & $63 \pm 5^{\S, \uparrow}$ \\
\hline Median (IQR) & $34(32-37)$ & $34(31-37)$ & $58(52-69)$ \\
\hline \multicolumn{4}{|l|}{$\mathrm{HbA}_{1 \mathrm{c}}, \%$} \\
\hline Mean \pm SEM & $5.3 \pm 0.1$ & $5.3 \pm 0.1$ & $7.9 \pm 0.5^{\text {§, }}$ \\
\hline Median (IQR) & $5.3(5.1-5.5)$ & $5.3(5.0-5.5)$ & $7.5(6.9-8.5)$ \\
\hline \multicolumn{4}{|l|}{ Fasting insulin, $\mathrm{pmol} / 1$} \\
\hline Mean \pm SEM & $36.4 \pm 3.2$ & $39.6 \pm 4.6$ & $67.9 \pm 12.2^{\S, \llbracket}$ \\
\hline Median (IQR) & $36.9(24.2-46.8)$ & $37.5(25.0-48.4)$ & $56.3(32.3-104.2)$ \\
\hline \multicolumn{4}{|l|}{ Fasting total cholesterol, $\mathrm{mmol} / \mathrm{l}$} \\
\hline Mean \pm SEM & $4.7 \pm 0.3$ & $5.0 \pm 0.2$ & $4.6 \pm 0.3$ \\
\hline Median (IQR) & $4.4(3.8-5.3)$ & $5.0(4.3-5.8)$ & $4.3(3.7-5.6)$ \\
\hline Fasting HDL-cholesterol, mmol/1 & & & \\
\hline
\end{tabular}




\begin{tabular}{|c|c|c|c|}
\hline Mean \pm SEM & $1.5 \pm 0.1$ & $1.4 \pm 0.1$ & $1.3 \pm 0.1$ \\
\hline Median (IQR) & $1.6(1.3-1.9)$ & $1.4(1.1-1.8)$ & $1.1(1.0-1.4)$ \\
\hline \multicolumn{4}{|c|}{ Fasting LDL-cholesterol, mmol/1 } \\
\hline Mean \pm SEM & $2.8 \pm 0.3$ & $3.1 \pm 0.2$ & $2.8 \pm 0.4$ \\
\hline Median (IQR) & $2.8(1.7-3.5)$ & $3.4(2.7-3.7)$ & $2.4(2.1-3.3)$ \\
\hline \multicolumn{4}{|c|}{ Fasting triacylglycerol, $\mathrm{mmol} / \mathrm{l}$} \\
\hline Mean \pm SEM & $0.7 \pm 0.1$ & $0.9 \pm 0.1$ & $1.9 \pm 0.4^{\S, \uparrow}$ \\
\hline Median (IQR) & $0.7(0.5-0.8)$ & $1.0(0.6-1.2)$ & $1.6(1.2-2.2)$ \\
\hline \multicolumn{4}{|l|}{ HOMA-IR } \\
\hline Mean \pm SEM & $1.1 \pm 0.1$ & $1.2 \pm 0.1$ & $4.6 \pm 1.0^{\S, \llbracket}$ \\
\hline Median (IQR) & $1.1(0.8-1.4)$ & $1.2(0.9-1.4)$ & $3.7(1.9-5.9)$ \\
\hline \multicolumn{4}{|l|}{ QUICKI } \\
\hline Mean \pm SEM & $0.39 \pm 0.01$ & $0.38 \pm 0.01$ & $0.32 \pm 0.01^{\S, \pi}$ \\
\hline Median (IQR) & $0.38(0.36-0.40)$ & $0.37(0.36-0.39)$ & $0.32(0.30-0.35)$ \\
\hline \multicolumn{4}{|l|}{ SBP, mmHg } \\
\hline Mean \pm SEM & $125 \pm 3$ & $118 \pm 2$ & $133 \pm 4^{\pi}$ \\
\hline Median (IQR) & $125(114-138)$ & $117(111-122)$ & $134(126-142)$ \\
\hline \multicolumn{4}{|l|}{$\mathrm{DBP}, \mathrm{mmHg}$} \\
\hline Mean \pm SEM & $78 \pm 2$ & $76 \pm 1$ & $85 \pm 3^{\pi}$ \\
\hline Median (IQR) & $78(71-87)$ & $76(73-79)$ & $85(81-96)$ \\
\hline \multicolumn{4}{|l|}{$\mathrm{cSBP}, \mathrm{mmHg}$} \\
\hline Mean \pm SEM & $116 \pm 3$ & $108 \pm 2^{\S}$ & $126 \pm 3^{\S, \emptyset}$ \\
\hline Median (IQR) & $116(109-125)$ & $108(106-112)$ & $125(117-133)$ \\
\hline \multicolumn{4}{|l|}{$\mathrm{cDBP}, \mathrm{mmHg}$} \\
\hline Mean \pm SEM & $80 \pm 2$ & $77 \pm 1$ & $86 \pm 3^{\pi}$ \\
\hline Median (IQR) & $80(73-88)$ & $77(74-80)$ & $86(83-98)$ \\
\hline
\end{tabular}

aPhysical activity data missing for $n=6 \mathrm{FH}-$ and $n=2$ type 2 diabetes participants

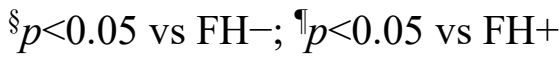

cDBP, central diastolic BP; cSBP, central systolic BP; DBP, diastolic BP; SBP, systolic BP 


\section{Figure legends}

Fig. 1 Metabolic effects of the MMC. Metabolic effects in $\mathrm{FH}-($ blue), $\mathrm{FH}+$ (purple) and type 2 diabetes (T2D; red) participants. (a) The $2 \mathrm{~h}$ blood glucose concentrations and (b) blood glucose AUC for MMC are shown. (c) The $2 \mathrm{~h}$ plasma insulin concentrations and (d) plasma insulin AUC for MMC are shown. (e) Changes in RER and (f) metabolic flexibility, expressed as the AUC for the change in RER from baseline in response to a MMC. Data are expressed as mean \pm SEM with individual data points. ${ }^{*} p<0.05$ vs 0 min for $\mathrm{FH}-; \dagger p<0.05$ vs 0 min for $\mathrm{FH}+; \ddagger p<0.05$ vs $0 \mathrm{~min}$ for T2D; $\$ t p<0.05 \mathrm{~T} 2 \mathrm{D}$ vs $\mathrm{FH}-$ and $\mathrm{FH}+$ at each time point; ${ }^{\S} p<0.05$ vs $\mathrm{FH}-;{ }^{\top} p<0.05$ vs $\mathrm{FH}+$

Fig. 2 Skeletal muscle microvascular responses to the MMC. Skeletal muscle microvascular haemodynamics at rest $(0 \mathrm{~min})$ and in response to a $\mathrm{MMC}(60 \mathrm{~min})$ in $\mathrm{FH}^{-}$(blue), $\mathrm{FH}+$ (purple) and type 2 diabetes (T2D; red) participants. Forearm muscle (a) MBV, (b) $\beta$ and (c) MBF. Data expressed as mean \pm SEM with individual data points. ${ }^{*} p<0.05,{ }^{* *} p<0.01$ vs 0 min

Fig. 3 Brachial artery responses to the MMC. Skeletal muscle brachial artery haemodynamics at rest $(0 \mathrm{~min})$ and in response to a $\mathrm{MMC}(60 \mathrm{~min})$ in $\mathrm{FH}-$ (blue), $\mathrm{FH}+$ (purple) and type 2 diabetes (T2D; red) participants. Brachial artery (a) diameter, (b) flow velocity and (c) blood flow. Data expressed as mean \pm SEM with individual data points. ${ }^{* *} p<0.01,{ }^{* * *} p<0.001$ vs 0 $\min$

Fig. 4 Vascular resistance and stiffness responses to the MMC. Forearm vascular resistance and stiffness at rest $(0 \mathrm{~min})$ and in response to a $\mathrm{MMC}(60 \mathrm{~min})$ in $\mathrm{FH}-($ blue $), \mathrm{FH}+$ (purple) and type 2 diabetes (T2D; red) participants. (a) Forearm vascular resistance, (b) pulse wave velocity and (c) augmentation index, adjusted to a heart rate of 75 beats per min (bpm) and 
participants' height. Data expressed as mean \pm SEM with individual data points. $* * * p<0.001$ vs 0 min; ${ }^{\S} p<0.05$ vs FH- at same time point; ${ }^{\circledR} p<0.05$ vs $\mathrm{FH}+$ at same time point 

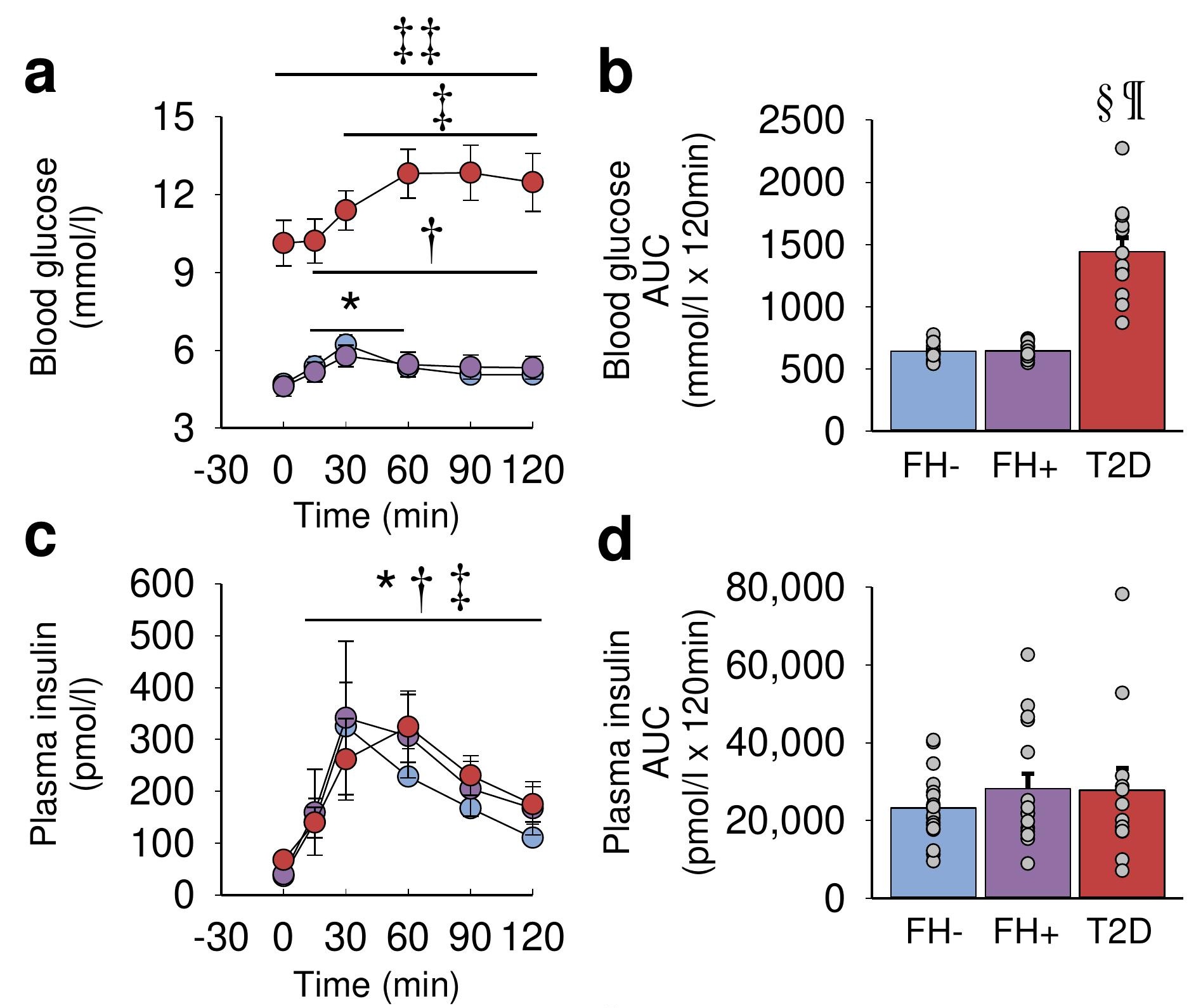

d

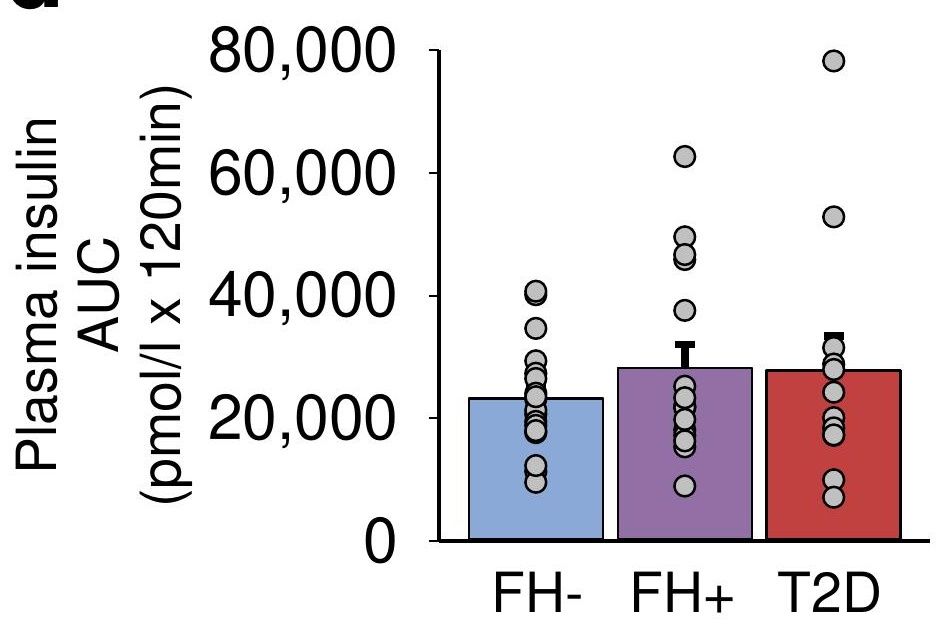

e

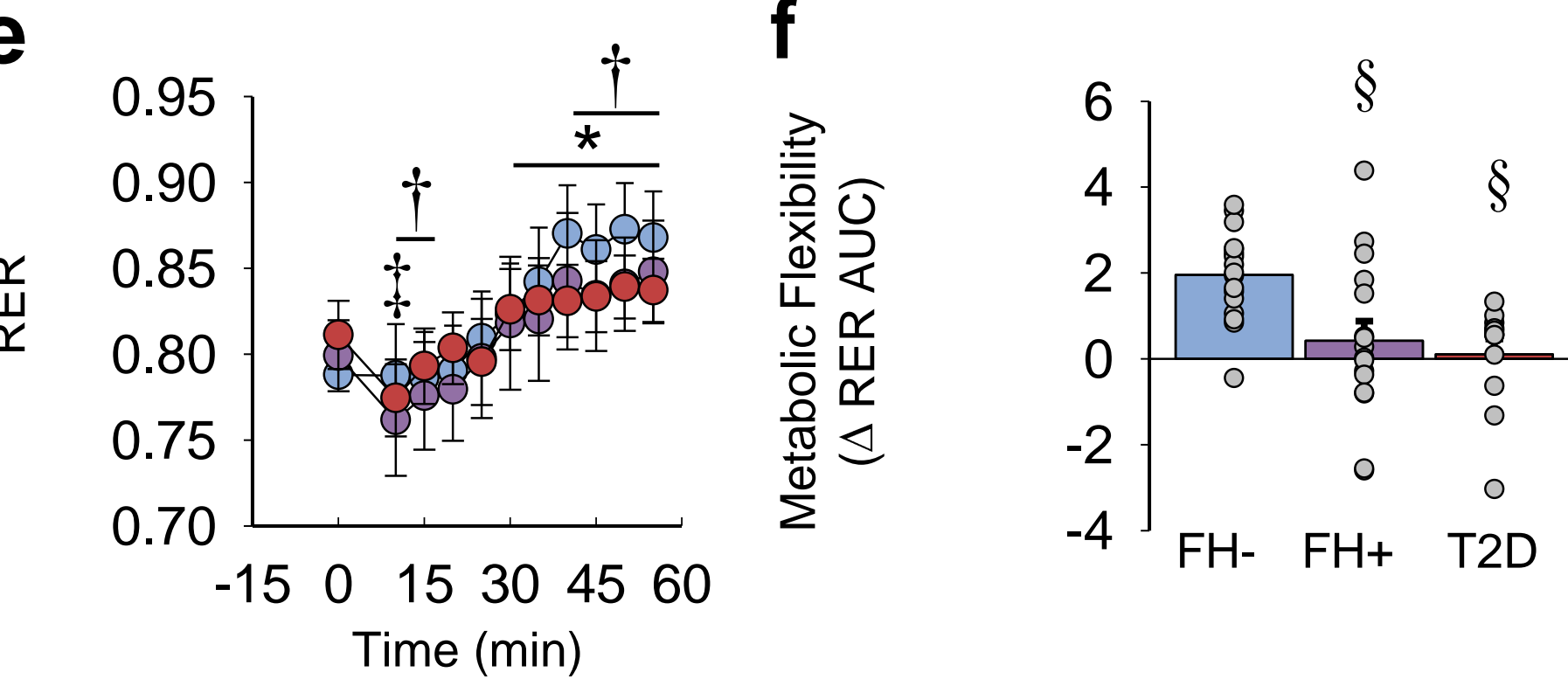

Figure 1 

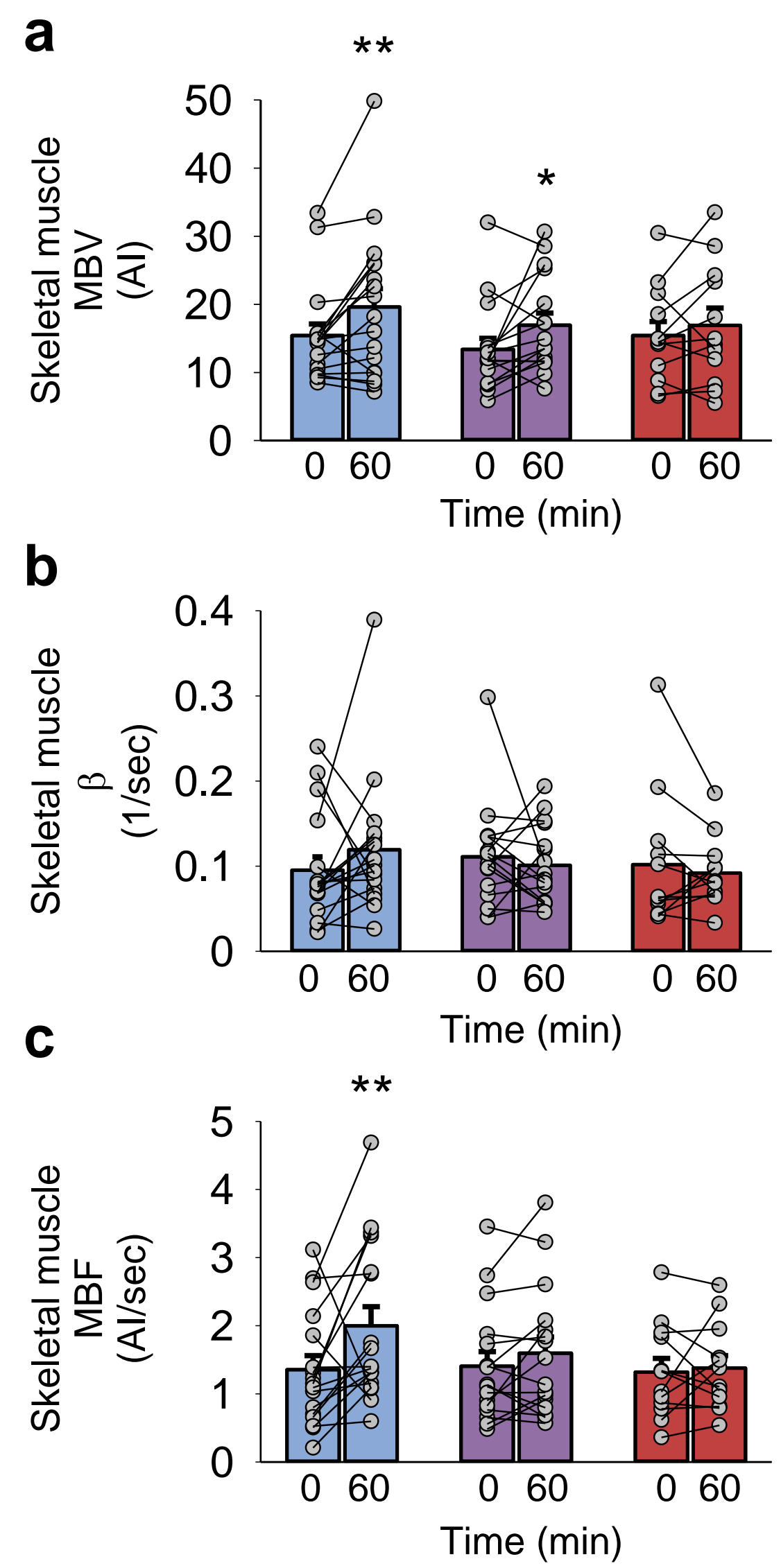

Figure 2 

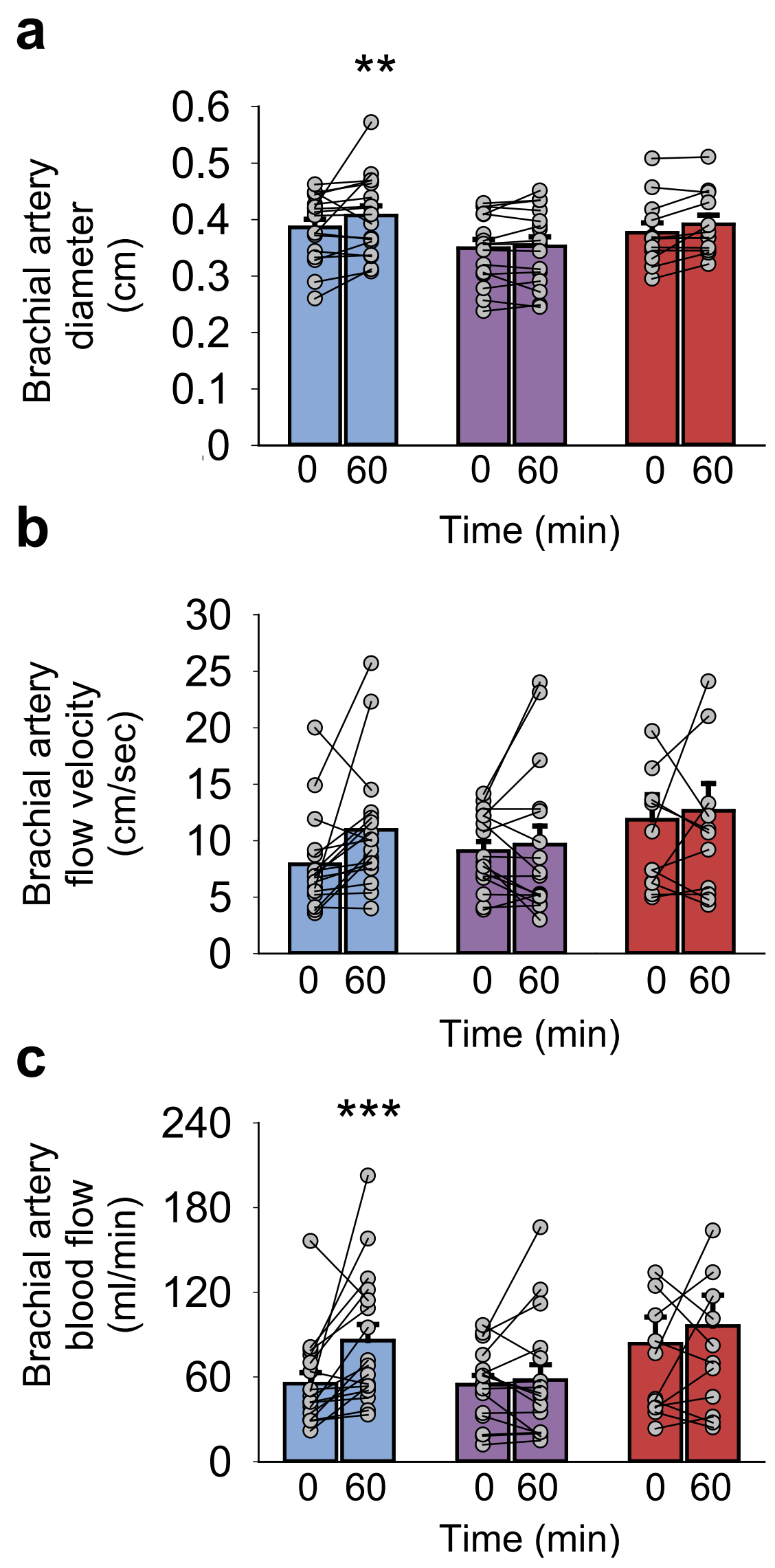

Figure 3 


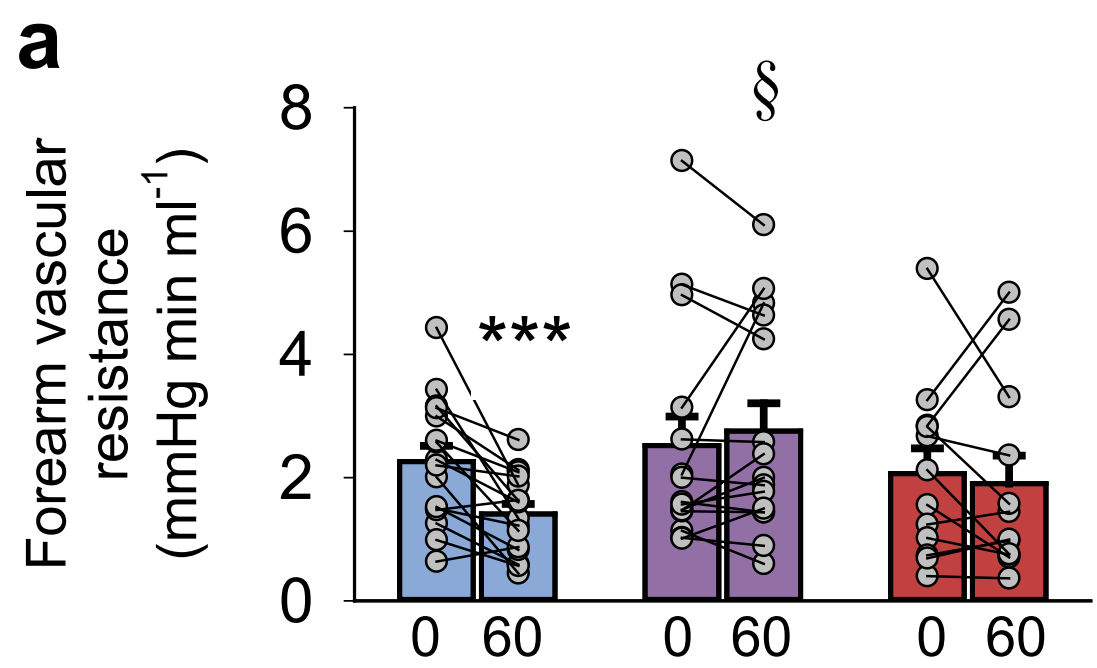

b
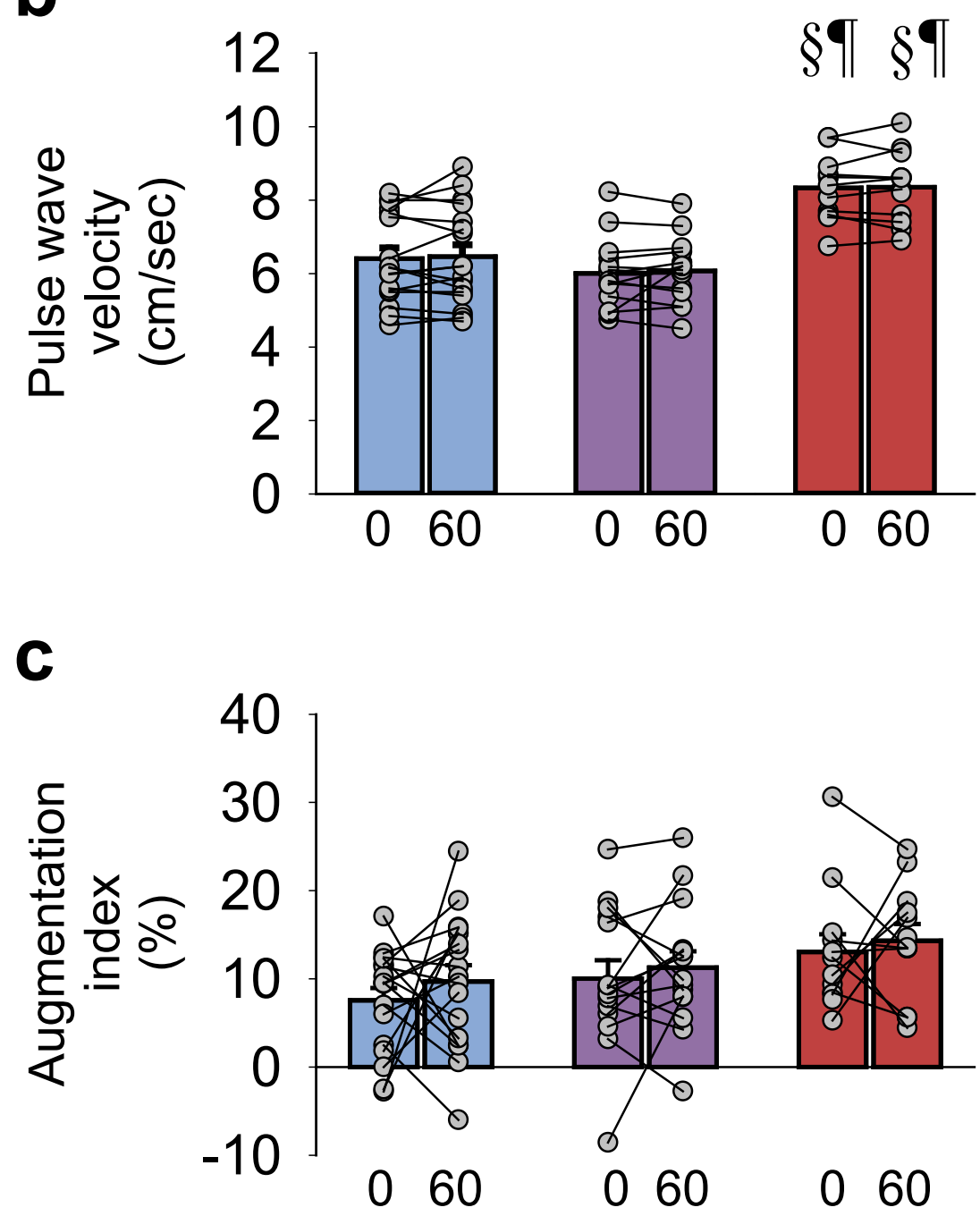

Figure 4 